\title{
Mutig und ermutigend
}

Liebe Leserin, lieber Leser,

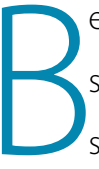

ei den deutschen Neuzulassungen hat sich im insgesamt rückläufigen Markt das Verhältnis der Fahrzeugsegmente verschoben. Während im vergangenen Jahr Oberklasselimousinen um knapp $14 \%$ weniger Käufer fanden, wuchs der Anteil verkaufter Kleinwagen um rund $20 \%$. Doch sind große SUV mit einem Zuwachs von mehr als $17 \%$ und Minivans weiter sehr gefragt. Lediglich 1,3\% der Neuwagen waren mit einem alternativen Antrieb ausgestattet.

Mit dem Elektroantrieb sollte eigentlich eine neue Ära im Fahrzeugleichtbau eingeläutet werden, da er dem Konstrukteur völlig neue Wege ebnet. Die Politik aber gab bislang zu wenig Anreize, indem sie mit der Nationalen Plattform Elektromobilität nur die Entwicklung von E-Fahrzeugen förderte, statt auch den Kunden eines solchen Vehikels beim Kauf zu unterstützen. Das ist zwar für den OEM attraktiv, der damit seine Entwicklungskosten überschaubar halten kann, bringt aber für den Verbraucher gar nichts.

Beim "Conversion Design" wird versucht, mit leichteren Werkstoffen in üblichen Konstruktionen Gewicht zu sparen. Doch nähert es sich deutlich der Grenze seiner Möglichkeiten, und so fragt man sich, wie es überhaupt mit der individuellen Mobilität weitergehen soll, wenn man es denn mit dem Klimaschutz ernst meint. Dieser wird ja immer als Initiator des Leichtbaus bemüht.

Verkehrspolitisch wirft man in dieser Hinsicht vor allem Nebelkerzen und bremst reflexhaft jede Debatte, die Radikaleres fordert. Der Ruf nach einer Umlegung der Kfz-Steuer auf den Liter Kraftstoff, die jenen Fahrer mehr belastet, der mehr verbraucht, verhallt regelmäßig ebenso schnell wie die Diskussion um ein sinnvoll limitiertes Tempo von etwa $130 \mathrm{~km} / \mathrm{h}$ auf Autobahnen. Der Staat möchte offenbar auf sichere Einnahmen aus jedem verkauften Liter Sprit und der Besteuerung des ruhenden Verkehrs auch künftig nicht verzichten.

Wir brauchen aber Maßnahmen, die den Kunden beim Umdenken unterstützen, ihm Anreize geben und für seine Verhaltensänderung belohnen. Diskussionen um Umweltzonen oder eine jährliche Hauptuntersuchung von Fahrzeugen, die älter sind als sechs Jahre, sind unsinnig und mehr als verzichtbar. Dadurch wird kein Anreiz geschaffen, sich ein angemessenes Auto zuzulegen. Was BMW mit seinem Projekt i durchzieht, ist mutig und ermutigend. Hoffentlich springt der Elan, konzeptionell völlig neue Wege zu gehen, auch auf andere Hersteller über. Der Leichtbau kann dann sein ganzes Potenzial ausschöpfen.

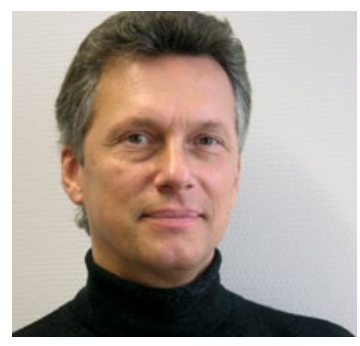

Dipl.-Ing. Ulrich Knorra Redakteur ulrich.knorra@springer.com 